\title{
Role of omega 3 in the prevention and treatment of breast cancer
}

\section{Sousa A.A1, Oliveira A.K.T2, Barroso M.I.T3, Medeiros L.B4}

1Estudante do Curso de Bacharelado em Nutrição da FSM; 2Estudante do Curso de Bacharelado em Nutrição da FSM; 3Estudante do Curso de Bacharelado em Nutrição da FSM; 4Docente/ Pesquisador do Departamento de Nutrição da FSM.

\section{ABSTRACT}

Introduction: Breast cancer is one of the major causes of morbidity and mortality in the world with a high prevalence in women. Researches on modifiable risk factors in breast cancer, including the role of diet, has received considerable attention from researchers around the world. Eicosapentaenoic acid (EPA) and docosahexaenoic acid (DHA), polyunsaturated fatty acids belonging to the Omega $3(\omega-3)$ family, are currently the most studied dietary factors and appear to be closely related to the decreased risk of developing cancer breast. Objective: Analyzing the role of $\omega-3$ in the treatment and reduction of risk of breast cancer. Methodology: A review of the literature was done by searching articles in the SCIELO, PUBMED and ACADEMIC GOOGLE databases. A total of 14 publications were selected from the years 2009 and 2017 because they fit the theme established in the present study. Results and Discussion: The consumption of fish and other foods rich in $\omega-3$ may be related to the decreased risk of breast cancer. Results from a recent review strongly suggest a potential role for EPA and DHA as complementary agents in combination with therapies against breast cancer. It is suggested that the action of $\omega$-3 in reducing the risk and development of breast cancer occurs from the reduction of the inflammation process and the inhibition of carcinogenesis by creating a cytotoxic environment that may be capable of inducing apoptosis and reducing proliferation. Conclusion: Further intervention studies are needed to confirm the role of $\omega-3$ in the adjuvant treatment of breast cancer. However, a large part of the research suggests that the ingestion of $\omega-3$ can be used as a strategy to prevent breast neoplasm, stimulating consumption in the diet of the general population, with a greater focus on females.

Keywords: Breast Cancer; Prevention; Treatment; Omega 3
*Correspondence to Author:

Sousa A.A

Estudante do Curso de Bacharelado em Nutrição da FSM

How to cite this article:

Sousa A.A, Oliveira A.K.T, Barroso M.I.T, Medeiros L.B. Role of omega 3 in the prevention and treatment of breast cancer.International Journal of Biomaterials and Nanobiotechnology. 2018, 1:1

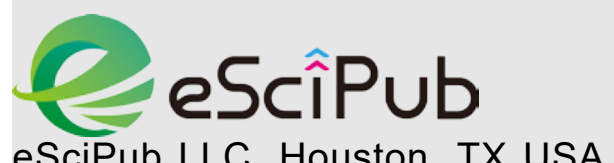
eSciPub LLC, Houston, TX USA. Website: http://escipub.com/ 